\title{
Power factor improvement using DCM Cuk converter with coupled inductor
}

\section{G. Ranganathan}

L. Umanand

\begin{abstract}
Most of the power factor regulator topologies in continuous conduction mode result in bulky magnetics, and in discontinuous conduction mode result in high harmonic content. To solve these problems a Cuk topology is presented in discontinuous conduction mode (DCM) with coupled inductors for power factor regulation, the unique feature exhibited by the converter that makes the converter better than the other converter in DCM operation for power factor regulation. Inductive coupling is used to transfer the ripple from the input to the output side thereby reducing the switching harmonics in the line current. Experimental results obtained on a $500 \mathrm{~W}$ prototype are also presented.
\end{abstract}

\section{List of symbols}

$D \quad=$ duty cycle

$D_{1}=$ fall time of inductor current

$F_{s}=$ switching frequency

$I_{p} \quad=$ peak inductor current

$i_{p} \quad=$ peak line current

$\boldsymbol{m}=$ modulation index

$V_{m}=$ peak input voltage

$I_{\text {base }}=$ fundamental line current at given load with no power loss

$k \quad=$ couling coefficient

$k_{e}=$ conduction parameter

$T_{s} \quad=$ switching time

$L_{e}=$ effective inductance

$L_{1} \quad=$ primary inductance

$L_{2}=$ secondary inductance

$L_{l p}=$ primary leakage inductance

$L_{l s}=$ secondary leakage inductance

\section{Introduction}

With the advent of new technologies in power processing systems, power factor improvement becomes necessary. Line currents drawn by the conventional diode rectifier filter capacitor are peaked pulse currents [1], which result in distortion of the utility line. The popular boost converter [2] requires complex control. The ripple currents are limited only by the size of the inductor. As the boost converter is operated in continuous conduction mode (CCM), the inductor required is large, which in turn will increase the crossover distortion. The boost converter in discontinuous conduction mode (DCM) also acts as an automatic current waveshaper. However, it requires a high conversion gain to reduce distortion. The flyback converter in DCM also can be used for power factor correction. As the ripple currents in DCM are high, the line harmonics have to be filtered. This paper discusses the Cuk converter in DCM, which acts as an automatic current waveshaper. It is also shown that by coupling the inductors the switching frequency harmonics in the line current can be significantly reduced.

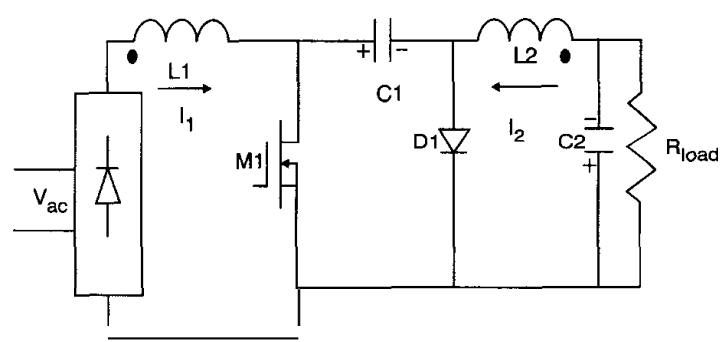

Fig.1 Cuk converter

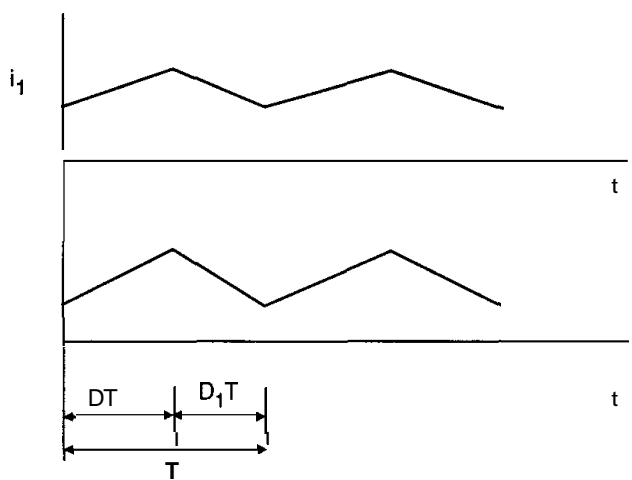

Fig.2 Inductor currents in CCM

\section{Cuk converter in DCM}

The Cuk converter shown in Fig. 1 employs circuit topology that enables it to have both input and output continuous current. Hence none of the problems present in conventional converters (boost, buck, buckboost) is present in the Cuk converter. In all converters 
except the Cuk converter, the onset of discontinuous inductor current occurs when the inductor current reaches zero before the end of one switching cycle. In the Cuk converter shown in Fig. 1, when the diode $\left(D_{1}\right)$ current reaches zero, the converter enters into discontinuous conduction mode. Assuming that the converter is operated in CCM the two inductor current waveforms are as shown in Fig. 2. Load current decreases to the point where the instantaneous output inductor current $i_{2}$ starts and finishes at zero, which would normally correspond to the onset of a discontinuous inductor current mode in all other converters but as the diode current is not zero neither input nor output current goes discontinuous at this stage.

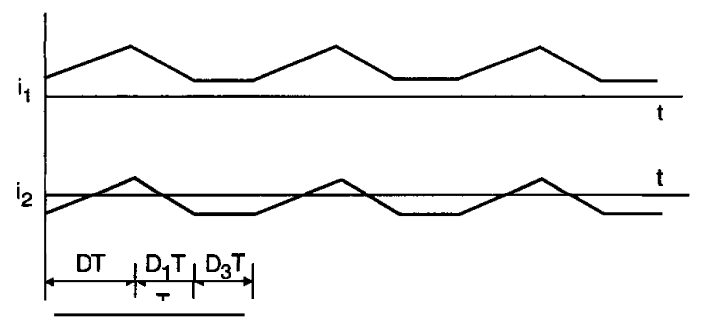

Fig.3 Inductor currents is $D C M$

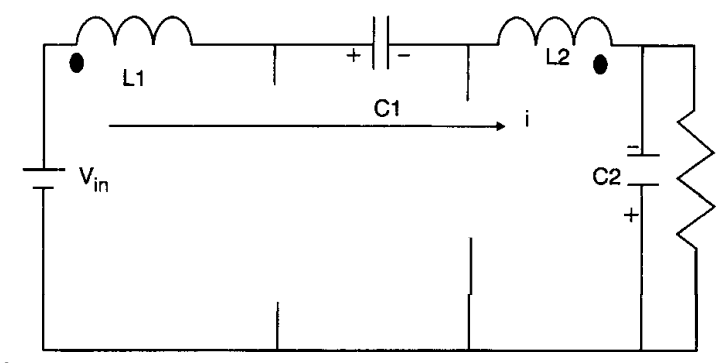

Fig.4 Thirdswitched network of Cuk converter in DCM

For further decrease in load current, $i_{2}$ becomes negative for parts of the switching cycle as shown in Fig. 3. Still the converter is in continuous conduction mode only, with two switching networks generated, even though the inductor current $i_{2}$ is flowing in the negative direction for part of the cycle. However, the average current $i_{2}$ is still positive thus maintaining output polarity. When the diode current reaches zero the diode opens up resulting in the third network and the onset of DCM in the Cuk converter. From Fig. 3 not only are the inductor currents in discontinuous conduction mode at the same time but they maintain equal decay intervals $D_{1}$ i.e. both the inductors enter the DCM at the same time. It is seen that the DCM current is clearly a nonzero current. At the onset of DCM, the third switched network of Fig. 4 appears for which both the switches are off. From Fig. 4 it can be shown that

$$
V_{1}=V_{1} \times \frac{D}{D_{1}}
$$

Assuming no power loss

$$
\frac{I_{1}}{I_{2}}=\frac{V_{2}}{V_{1}}=\frac{D}{D_{1}}
$$

where $I_{1}$ and $I_{2}$ are the average input and output currents. The average currents can be expressed as

$$
I_{1}=\frac{V_{1}}{2 \times L_{1}} \times D \times T_{s} \times\left(D+D_{1}\right)+i
$$

and the average output current can be expressed as

$$
I_{2}=\frac{\ddot{V_{1}}}{2 x L_{2}} \times D \times T_{s} \times\left(D+D_{1}\right)-i
$$

By defining

and

$$
\frac{1}{L_{e}}=\frac{1}{L_{1}}+\frac{1}{L_{2}}
$$

$$
M=\frac{V_{o}}{V_{m}}
$$

the average input current can now be expressed as

$$
I_{\text {lavg }}=I_{1}=\frac{1}{2} \times D^{2} \times T_{s} \times \frac{1}{L_{e}} \times V_{1}(t)
$$

From eqn. 6 the input current follows the input voltage if the duty cycle is kept constant. The boundary between CCM and DCM operation for the Cuk converter is defined by the dimensionless parameter (conduction parameter) $k$, defined by

$$
k_{e}=\frac{2 \times L}{R_{\text {load }} \times T_{s}}
$$

For the Cuk converter as PFR to operate in DCM the conduction parameter $k_{e}$ [2] should satisfy the following condition:

$$
k_{e} \leq \frac{1}{2 \times(M+|\sin \omega t|)^{2}}
$$

At the border between DCM and CCM this inequality is equal or smaller in DCM and greater in CCM. The peak line current is given by

$$
i_{p}=\frac{D^{2} \times T_{s} \times V_{m}}{2 \times L}
$$

The peak inductor current in a switching cycle is given by

$$
\begin{gathered}
I_{P}^{c u k}-\frac{V_{m} \times D \times T_{s}}{L_{1}}+i \\
\imath=\iota_{p} \times \frac{D-D_{\mathrm{T}}}{2 D}
\end{gathered}
$$

Substituting eqns. 11 and 9 in eqn. 10 and rearranging produces

$$
I_{p}^{c u k}=\sqrt{\frac{i_{p} \times V_{m} \times T_{s}}{L_{1}}} \times \frac{\left(2+\left(D-D_{1}\right)\right)}{2}
$$

For the Cuk converter to be in DCM for the entire line cycle of AC input voltage [2], the conduction parameter at $\omega t=90^{\circ}$ is given by

$$
\frac{2 \times L_{e}}{R_{\text {load }} \times t}=\frac{1}{2 \times(M+1)^{2}}
$$

where $M$ is the ratio of the output voltage to the peak input voltage. Substituting eqn. 13 in eqn. 12 and rearranging gives

$$
I_{p}^{c u k}=\sqrt{2 \times i_{p} \times I_{o} x(M+1)^{2} \frac{1}{M}} \times \frac{\left(2+\left(D-D_{1}\right)\right)}{2}
$$

Defining the base current as the line current that flows at the unity power factor condition for a given load, and from the power equivalence relation (assuming no loss) $P_{o}=P_{\text {in }}$,

$$
\begin{gathered}
\frac{V_{m} \times I_{p}^{\text {line }}}{2}=V_{o} \times I, \\
I_{\text {base }}=2 \times M \times I_{o}
\end{gathered}
$$


The per unit peak inductor current can be obtained as

$$
I_{\text {peak }}^{\text {inductor }}(p . u)=\frac{M+1}{M} \times \frac{2+\left(D-D_{1}\right)}{2}
$$

Summarising the Cuk converter operated in DCM, the line current follows the line voltage provided that the switching frequency is very high compared with the line frequency and the two inductors operate in the linear magnetic region.

\section{Comparison with other DCM converters}

The Cuk converter in DCM shows better current-shaping properties compared with the more popular boost and flyback converters. An active power-factor correction circuit can process either total input power or just a portion of the input power. Total power processing, achieved by flyback converter as shown in Fig. 5, provides full control of input power flow. Unlike the boost converter it offers partial control of power flow. This gives high efficiency compared with other converters.

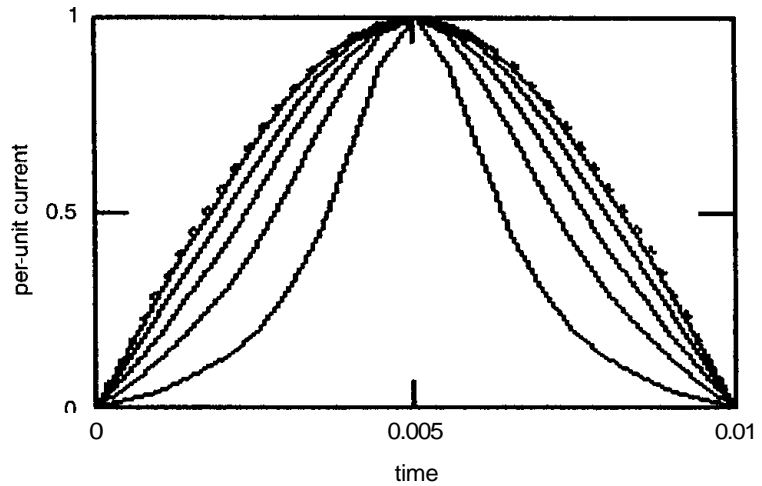

Fig.5 Lime currents for different values of $m$

\section{I Boost converter}

In the more popular boost converter, when operated in DCM, the on-time of a switching cycle is controlled by the output voltage error signal and is essentially constant over an AC line cycle. With the switching frequency much higher compared with the $\mathrm{AC}$ line frequency, the input voltage is assumed constant over a switching cycle. The peak value of the inductor current is proportional to the input voltage in each switching cycle. As the input voltage varies sinusoidally, the peak inductor current follows the sinewave input voltage. But in the case of the Cuk converter in DCM, the average current in a switching cycle varies sinusoidally over an AC cycle. Hence the current distortion is greater in a boost converter than in a Cuk converter.

In the voltage-follower boost converter, the on-time of the switch is almost constant over an AC cycle. With sinusoidal input voltage $V_{\text {in }}=V_{m} \times \sin \omega t$, the peak inductor current is given by

$$
\begin{aligned}
I_{P}^{\text {boost }} & -\frac{V_{\text {in }} \times T_{\text {on }}}{L_{i}} \\
& =\frac{V_{m} \times D \times T_{s} \times \sin (\omega t)}{L_{i}}
\end{aligned}
$$

where $T_{s}$ is the period of the switching cycle and $D$ is the duty cycle. The peak inductor current follows an envelope $K \times V_{m} \times \sin w t$. At the end of the on-time the diode starts conducting and the input energy along with the stored energy in the inductor is discharged to the output. The inductor current falls to zero. The

$$
\begin{aligned}
& I_{\text {lavg }}=I_{\text {onavg }}+I_{o f f a v g} \\
& I_{\text {onavg }}=\frac{V_{i n}^{2} \times D^{2} \times T_{s}}{2 \times L_{i}}
\end{aligned}
$$

and

$$
I_{\text {offavg }}=\frac{V_{i n}^{2} \times D^{2} \times T_{s}}{2 \times L_{i} \times\left(V_{o}-V_{i n}\right)}
$$

Therefore the average inductor current is given by

$$
I_{\text {lavg }}=\frac{D^{2} \times T \times V_{o}}{2 \times L_{i}} \times \frac{m \times \sin (\omega t)}{1-m \times \sin (\omega t)}
$$

where $\boldsymbol{m}$ is the modulation index defined by $\mathrm{m}=V_{m} /$ $V_{o}$. From eqn. 22 it is clear that when the modulation index $\mathrm{m}$ is very small, line current is almost sinusoidal. As the index approaches unity line current is more distorted. Fig. 5 shows the normalised line current waveforms with different modulation indices. It is clear that as the modulation index is close to one the line currents are distorted, while if it is much smaller the line currents are more sinusoidal. Fig. 6 shows the total harmonic distortion with varying modulation index.

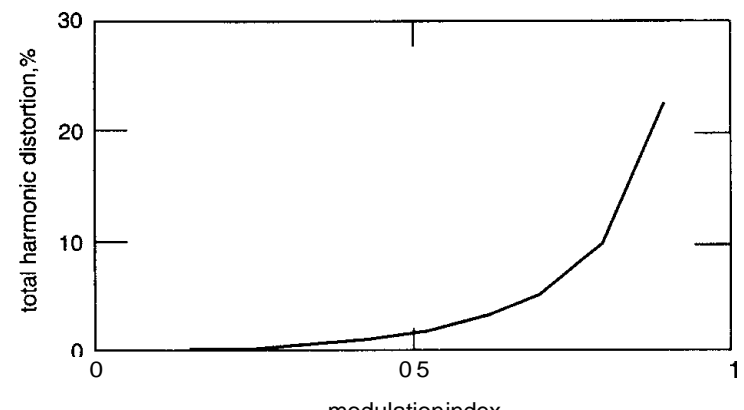

Fig.6 Total harmonic distortion for different values of $m$

It is also seen [3] that as long as the modulation index is less than 0.8 , powerfactor is always greater than 0.95 . But it is evident from eqn. 8 that in the Cuk converter the line current follows the line voltage irrespective of the modulation index. So the power factor is always higher than 0.99 and is better than the boost converter in DCM. The boundary between CCM and DCM operation for boost converter is defined by the dimensionless parameter (conduction parameter) $k_{e}$ [2], defined by

$$
k_{e}=\frac{2 \times L}{R_{\text {load }} \times T_{s}}
$$

For the boost converter as PFR to operate in DCM the conduction parameter $k_{e}$ should satisfy the following condition

$$
k_{e} \leq \frac{m-|\sin \omega t|}{2 \times m 3}
$$

At the border between DCM and CCM this inequality is equal or smaller in DCM and greater in CCM. For the boost converter the input line current is given by eqn. 22. Then at $w t=90^{\circ}$, from eqn. 22 , the average peak line current is given by

$$
i_{p}=\frac{D^{2} \times T_{s} \times V_{o}}{2 \times L_{i}} \times \frac{m}{(1-m)}
$$

The peak inductor current in a switching cycle is given by

$$
I_{p}^{\text {boost }}-\frac{V_{m} \times D \times T_{s}}{L_{\text {boost }}}
$$


Substituting eqn. 25 in eqn. 26 and rearranging,

$$
I_{p}^{\text {boost }}=\sqrt{\frac{2 \times i_{p} \times V_{m} \times(1-m)}{L_{\text {boost }}}}
$$

For the boost converter to be in DCM for the entire line cycle of $\mathrm{AC}$ input voltage [2],

$$
\frac{2 \times L_{\text {boost }}}{R_{\text {load }} \times t}=\frac{M-1}{2 \times M^{3}}
$$

where $M=1 / m$, the ratio of the output voltage to the peak input voltage. Substituting eqn. 28 in eqn. 27 and rearranging

$$
I_{p}^{b o o s t}=\sqrt{8 \times i_{p} \times I_{o} \times M}
$$

The per-unit current can be obtained as

$$
I_{p}^{\text {inductor }}(p . u)=2
$$

The per-unit current is derived on the assumption that the the modulation index $\boldsymbol{m}$ is chosen such that the total harmonic distortion is less. It is seen that the maximum peak inductor current is twice the maximum peak line current for the given load condition. It will be shown that the peak inductor current stress for a given inductor is lower in the case of the Cuk converter with coupled inductor, as explained in Section 4.

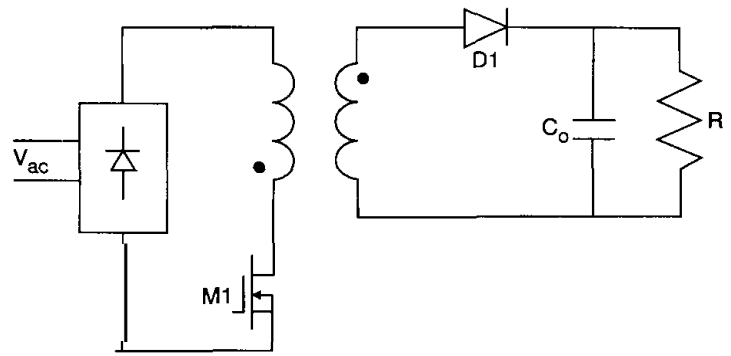

Fig.7 Flyback converter us PFR

\subsection{Flyback converter}

The flyback converter shown in Fig. 7 when operated in DCM acts as an automatic current waveshaper. In DCM all the stored energy in the inductor during the on-time of the switch is delivered back to the output during the off-time. The peak inductor current in a switching cycle can be expressed as

$$
I_{\text {peak }}^{\text {flyback }}=V_{m} \times \sin \omega t \times \frac{t_{\text {on }}}{L_{\text {flyback }}}
$$

The inductor current is discontinuous with a sinusoidal envelope that is determined by the peak inductor current. If the switching frequency is higher than the line frequency, then

$$
\begin{gathered}
I_{\text {line }}=\frac{L_{\text {flyback }} \times I_{p}^{2}}{V_{m} \times 2 \times T_{s}} \times \sin w t \\
I_{\text {lineavg }}=\frac{t_{\text {on }} \times I_{p}^{\text {flyback }}}{2 \times T_{s}} \times \sin \omega t
\end{gathered}
$$

It is seen from eqn. 33 that the line current follows a sinusoidal envelope if the on-time is kept constant. The DCM operation of the flyback converter is again governed by the conduction parameter. The conduction parameter should satisfy the following condition for the flyback converter to operate in DCM:

$$
k_{e} \leq \frac{1}{2 \times(M+|\sin \omega t|)^{2}}
$$

With the flyback converter operating at the border between CCM and DCM at the peak of the input voltage, the conduction parameter is that at $\omega t=90 "$. Substituting eqns. 34 and 32 in eqn. 33 and rearranging,

$$
I_{p}^{\text {flyback }}=\sqrt{8 \times I_{p}^{\text {line }} \times I_{o} \times \frac{(M+1)^{2}}{M}}
$$

Similar to the case of the boost converter, the per-unit current can be obtained as

$$
I_{\text {peak }}^{\text {inductor }}(p . u)=2 \times \frac{\left(V_{o}+V_{m}\right)}{V_{o}}
$$

It can be seen that the peak current stress in case of the Cuk converter will be less owing to the coupled inductor, as explained in Section 5. When compared with the boost converter, the flyback converter gives higher power factor but the peak current stresses are higher.

\section{Coupled-inductor Cuk converter}

As the instantaneous values of the voltage across the two inductors of the Cuk converter are the same the two inductors can be coupled into one magnetic structure. The two inductors can be coupled without affecting the basic DC conversion property, provided the resulting transformer has a 1:I transfer ratio. The total magnetising current is the sum of the currents flowing in the inductor. The characteristics of the coupled inductor when analysed show a profound effect in the reduction of the input and the output ripple currents.

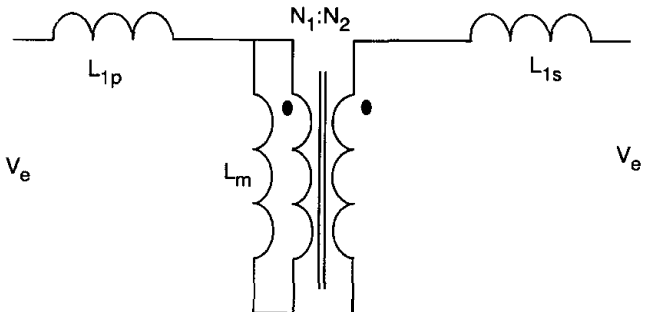

Fig. 8 Equivalent circuit model of coupled inductor

\subsection{Ripple currents in coupled inductor Cuk converter}

The equivalent circuit model of the coupled inductor shown in Fig. 8 is used to analyse the ripple. Writing the KVL equations

$$
\begin{array}{rl}
L_{1} x \frac{d i_{1}}{d t}+L, \quad x \frac{d i_{2}}{d t} & =V_{e} \\
L 2 x \frac{d i_{2}}{d t}+L_{m} x & d i_{1} \\
d t & =V_{e}
\end{array}
$$

where $L_{1}$ and $L_{2}$ are the self inductances of the two windings, respectively. When the switch is on the equations can be expressed as

$$
\left[\begin{array}{l}
\frac{d i_{1}}{d t} \\
\frac{d i_{2}}{d t}
\end{array}\right]=\frac{1}{L_{1} L_{2}-L_{m}^{2}}\left[\begin{array}{cc}
L_{2} & -L_{m} \\
-L_{m} & L_{1}
\end{array}\right]\left[\begin{array}{l}
V_{i n} \\
V_{i n}
\end{array}\right]
$$

The ripple currents can be derived as

$$
\begin{aligned}
\Delta i_{1} & =\frac{\left(L_{2}-L_{m}\right) V_{i n} D T_{s}}{L_{1} L_{2}-L_{m}^{2}} \\
\Delta i_{2} & =\frac{\left(L_{2}-L_{m}\right) V_{i n} D T_{s}}{L_{1} L_{2}-L_{m}^{2}}
\end{aligned}
$$

The input and output ripple has reduced considerably (almost two times) owing to coupling when compared with the uncoupled part. 


\subsection{Zero-ripple condition}

By merely coupling the two inductors, and provided that the leakage inductances are positive (mutual inductance is positive by the dot convention), both effective inductances are increased, thus resulting in the reduction of both input and output ripple. When the two leakage inductances substantially differ there is an unbalanced increase in the effective inductances. If $L_{l s}$ $\leq L_{l p}$ the secondary effective inductance changes by a very small amount, but the primary effective inductance increases greatly owing to the proportional dependence on $L_{l p} / L_{l s}$. From eqns. 41 and 40 the effective primary and secondary inductances after coupling can be obtained as

$$
\begin{aligned}
& L_{e f f 1}=\frac{L_{1} L_{2}-L_{m}^{2}}{L_{2}-L_{m}} \\
& L_{e f f 2}=\frac{L_{1} L_{2}-L_{m}^{2}}{L_{1}-L_{m}}
\end{aligned}
$$

On simplification

$$
\begin{aligned}
& L_{e f f 1}=\frac{L_{m} \times\left(L_{l p}+L_{l s}\right)}{L_{l s}}+L_{l p} \\
& L_{e f f 2}=\frac{L_{m} \times\left(L_{l p}+L_{l s}\right)}{L_{l p}}+L_{l s}
\end{aligned}
$$

If $L_{l s}$ is made zero, the primary effective inductance tends to infinity and the primary ripple goes to zero. Similarly, if $L_{l p}$ is made zero the secondary inductance tends to infinity and the secondary ripple goes to zero. It is also seen that as $L_{l s}$ is made zero, the effective secondary inductance reduces from $L_{2}+L$, and becomes

$$
L_{e f f 2}=L_{m}
$$

This results in an increase in the secondary ripple. In effect, the primary ripple has been transferred from the primary and flows in the secondary side. Defining coupling coefficient $k$ and the turns ratio $n$ as

$$
\begin{gathered}
k=\frac{L_{m}}{\sqrt{L_{1} \times L_{2}}} \\
n=\frac{N_{2}}{N_{1}}=\sqrt{\frac{L_{2}}{L_{1}}}
\end{gathered}
$$

the zero input ripple condition can be expressed as

$$
k=\frac{L_{m}}{\sqrt{L_{1} \times L_{2}}}=n
$$

and the zero output ripple condition as

$$
k=\frac{L_{m}}{\sqrt{L_{1} \times L_{2}}}=\frac{1}{n}
$$

Hence by proper adjustment of the turns ratio and the coupling coefficient (by adjusting airgap), zero input current ripple or zero output current ripple is achieved. It is also seen that for zero input ripple, $\boldsymbol{k}=n$ which implies that the turns ratio has to be less than one, i.e. $N_{2} / N_{1}<1$ and for the zero output ripple $N_{2} / N_{1}>1$. Zero ripple can also be acheived by tightly coupling the two inductors and then adding an external inductor on the side in which the ripple has to be reduced and by proper tuning of the value of the external inductor with the turns ratio fixed.

\section{Design details and experimental results}

A 500W prototype Cuk converter acting as an automatic current shaper was designed. Output voltage was
$50 \mathrm{kHz}$ was chosen. Pulse width modulated voltage control is used for control. A coupled inductor adjusted for zero input ripple to reduce the line harmonics was used. To operate the Cuk converter in DCM, from eqn. 8 ,

$$
L_{e} \leq \frac{R_{\text {load }} T_{S}}{2(1+M)^{2}}
$$

Once the ripple is transferred to the primary the ripple current is determined by the secondary inductance. Substituting the values $V_{o}=360 \mathrm{~V}, V_{\text {in }}=150, R_{\text {load }}=$ 259 , the secondary inductance is

$$
L_{e} \leq \frac{259 \times 20 \times 10^{-6}}{2(1+2)^{2}}=224 \mu \mathrm{H}
$$

A suitable core was selected. Using 30 turns for the primary and 26 turns for the secondary the leakage and self inductances are measured. The turns ratio $n=$ 0.866 . The airgap is adjusted till the coupling coefficient is also around 0.866 , and the mutual inductance is measured from the two possible series connections, namely the series-aiding $\left(L_{s a}\right)$ and the series-opposing connection $\left(L_{s o}\right)$

$$
L_{m}=\frac{L_{S a}-L_{s o}}{4}
$$

By adjusting the airgap the following measurements are made: $L_{,},=352 \mu \mathrm{H}, L_{s o}=19.4 \mu \mathrm{H}, L_{1}=112 \mu \mathrm{H}$ and $L_{2}$ $=83.45 \mu \mathrm{H}$. The mutual inductance is then $L,=$ $83.15 \mu \mathrm{H}$. It is seen that the mutual inductance is very close to the secondary inductance which ensures that the zero ripple condition is acheived. (As the inductor was not tightly wound leakage is present.) The coupling coefficient from eqn. 48 is $k=0.860$. The turns ratio is given by

$$
n=\sqrt{\frac{L_{2}}{L_{1}}}=0.860
$$

For this value of effective inductance the duty ratio and the peak currents are recalculated. Fig. 9 shows the input line voltage and line current with coupled inductor at full load and low line. Fig. 10 shows the same for an uncoupled inductor. The switching harmonics are considerably reduced with a coupled inductor. Fig. 11 shows the input and output currents in a switching cycle with an uncoupled inductor. Fig. 12 shows the same with a coupled inductor. The reduction in the input ripple is seen to be $40 \mathrm{~dB}$.

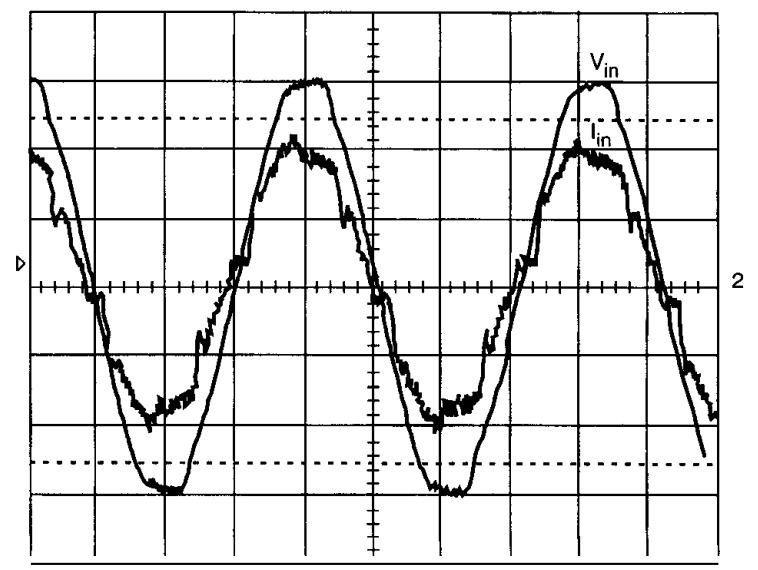

$\longleftarrow 6.0 \mathrm{~ms}$

Fig.9 Line current and line voltage waveforms of a $500 \mathrm{~W}$ coupled-

inductor Cuk converter
$V_{\text {in }}=150 \mathrm{~V} ; V_{0}=360 \mathrm{~V}$; current: $2 \mathrm{~A} / \mathrm{div} ;$ voltage: $70 \mathrm{~V} / \mathrm{div} ;$ time: $5 \mathrm{~ms} / \mathrm{div}$ 


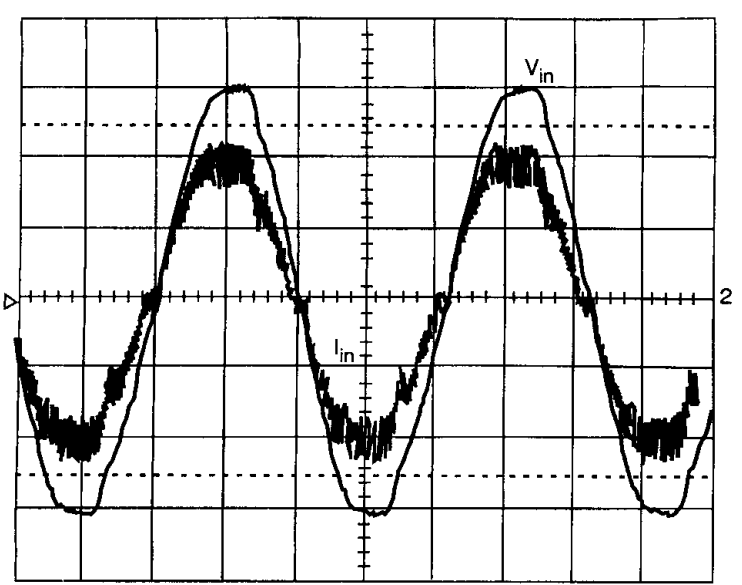

Fig. 10 Line current and line voltage waveforms of $500 \mathrm{~W}$ uncoupled inductor Cuk converter

$V_{i n}=150 \mathrm{~V} ; \mathrm{V},=360 \mathrm{~V}$; current' $2 \mathrm{~A} / \mathrm{div}$; voltage: $70 \mathrm{~V} / \mathrm{div}$; time: $5 \mathrm{~ms} / \mathrm{div}$

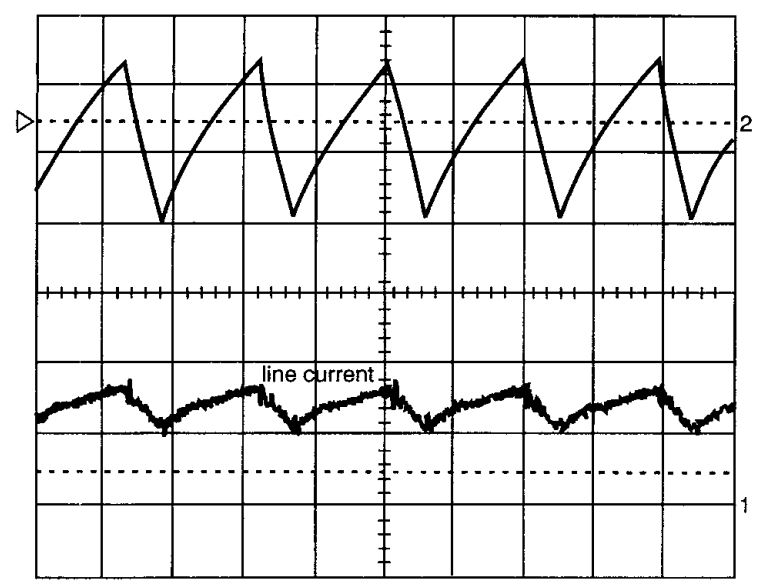

$\longleftarrow 664 \mu \mathrm{s}$

Fig.11 Uncoupled inductor currents in a switching cycle Secondary current 5A/div; primary: $2 \mathrm{~A} / \mathrm{div}$; time: $10 \mathrm{us} / \mathrm{div}$

\section{Conclusions}

The Cuk converter behaves as an automatic current waveshaper with no current control. Switching frequency harmonics can be reduced by coupling the two inductors as explained. Nonidealities inherent to PFR

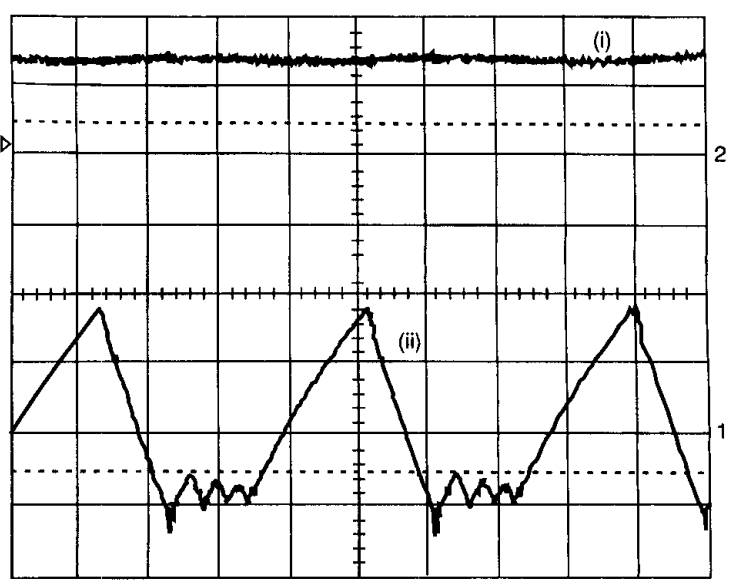

$\longleftarrow 6000 \mathrm{~ms}$

Fig.12 Coupled-inductorcurrents $\boldsymbol{m}$ snitching cycle (I) Line current, (a) secondary inductor current

Secondary current $5 \mathrm{~A} / \mathrm{div} ;$ primary $2 \mathrm{~A} / \mathrm{div} ;$ time $10 \mathrm{us} / \mathrm{div}$

topologies are the lag effect in the input current at zero crossing and the switching harmonics. The switching harmonics are reduced by coupling the inductors. Another Cuk converter following this PFR stage can be designed for zero output ripple thus eliminating ripple from the input as well as the output. The lag effect is negligible as the inductance used is much smaller in the case of DCM. Further isolation can be given by introducing high-frequency transformer isolation. The transformer and the two inductors can be integrated into one magnetic structure and both the output and the input ripple can be transferred to the transformer where the AC ripple inherently exists as the magnetising current of the transformer

\section{References}

1 BRKOVIC, M., and CUK, S.: 'Input current shaper using Cuk converter', Proc. IEEE, 1992, pp. 5532-5539

2 SEBASTIAN, J., COBOS, J.A., LOPERA., J.M., and UCEDA, J.: 'The determination of boundaries between continuous and discontinuous conduction mode in PWM DC-to-DC converters used as power factor preregulators', IEEE Trans. Power Electron. as power facto
$1995, \mathbf{1 0},(5)$

3 LIU, K.H., and LIN, Y.L.: 'Current waveform distortion in power factor correction circuits employing discontinuous mode boost converters'. Proceedings of IEEE PESC, pp. 780-791

4 CUK, S.: 'Coupled inductor and integrated magnetics techniques in power electronics'. Proceedings of IECE, Japan, 1983. pp. $347-$ 